\title{
Pseudomonas aeruginosa adapts its iron uptake strategies in function of the type of infections
}

\author{
Pierre Cornelis $^{1,2 *}$ and Jozef Dingemans ${ }^{1,2}$ \\ ${ }_{1}^{1}$ Research Group Microbiology, Department of Bioengineering Sciences, Vrije Universiteit Brussel, Brussels, Belgium \\ ${ }^{2}$ Department Structural Biology, VIB, Vrije Universiteit Brussel, Brussels, Belgium
}

\author{
Edited by: \\ Mathieu F. Cellier, Institut National \\ de la Recherche Scientifique, \\ Canada \\ Reviewed by: \\ Angela Wilks, University of \\ Maryland, USA \\ Isabelle J. Schalk, Centre National \\ de Recherche Scientifique, France \\ *Correspondence: \\ Pierre Cornelis, Research Group \\ Microbiology, Department of \\ Bioengineering Sciences, \\ Department Structural Biology \\ Brussels, VIB, Vrije Universiteit \\ Brussel, Pleinlaan 2, 1050 Brussels, \\ Belgium \\ e-mail:pcornel@vub.ac.be
}

Pseudomonas aeruginosa is a Gram-negative $\gamma$-Proteobacterium which is known for its capacity to colonize various niches, including some invertebrate and vertebrate hosts, making it one of the most frequent bacteria causing opportunistic infections. P. aeruginosa is able to cause acute as well as chronic infections and it uses different colonization and virulence factors to do so. Infections range from septicemia, urinary infections, burn wound colonization, and chronic colonization of the lungs of cystic fibrosis patients. Like the vast majority of organisms, $P$. aeruginosa needs iron to sustain growth. $P$. aeruginosa utilizes different strategies to take up iron, depending on the type of infection it causes. Two siderophores are produced by this bacterium, pyoverdine and pyochelin, characterized by high and low affinities for iron respectively. P. aeruginosa is also able to utilize different siderophores from other microorganisms (siderophore piracy). It can also take up heme from hemoproteins via two different systems. Under microaerobic or anaerobic conditions, $P$. aeruginosa is also able to take up ferrous iron via its Feo system using redox-cycling phenazines. Depending on the type of infection, $P$. aeruginosa can therefore adapt by switching from one iron uptake system to another as we will describe in this short review.

Keywords: Pseudomonas aeruginosa, iron, siderophores, pyoverdine, pyochelin, heme uptake, Feo, phenazines

\section{Pseudomonas aeruginosa}

Pseudomonas aeruginosa is a ubiquitous $\gamma$-proteobacterium found in many diverse environments, such as water or the rhizosphere and it produces a large array of colonization and virulence factors allowing it to establish itself in plants, nematodes, insects, and in mammals, including humans where it can cause different types of infections (Rahme et al., 1997; Mahajan-Miklos et al., 1999; Goldberg, 2000; Lyczak et al., 2000, 2002; Pukatzki et al., 2002). P. aeruginosa produces different virulence factors, including the extracellular exotoxin A, extracellular proteases, lipase, phospholipases, and toxins injected via the type III secretion system (Coggan and Wolfgang, 2012; Jimenez et al., 2012; Balasubramanian et al., 2013). The production of many virulence factors is coordinately regulated by small diffusing molecules, via a mechanism termed quorum sensing (Juhas et al., 2005; Schuster and Greenberg, 2006; Venturi, 2006; Williams et al., 2007; Girard and Bloemberg, 2008; Winstanley and Fothergill, 2009). The other important factor allowing colonization of the host is the efficient uptake of iron by the bacterium. In the mammalian host iron is not freely available since it is either present in the heme molecule found in hemoproteins (hemoglobin, cytochromes...) or strongly chelated by extracellular proteins (transferrin and lactoferrin) (Cornelissen and Sparling, 1994). P. aeruginosa is able to switch its lifestyle from planktonic unicellular to a sessile form in biofilms (Goodman et al., 2004; Mikkelsen et al., 2011). Two conflicting sensor systems control the switch from planktonic to sessile lifestyle: RetS for the switch to acute virulence with the production of toxins and expression of type III secretion system, and LadS/GacS for the conversion to the sessile mode with the expression of genes involved in type VI secretion system, production of exopolysaccharides, resulting in biofilm formation and chronic infections (Goodman et al., 2004; Mikkelsen et al., 2011; Coggan and Wolfgang, 2012; Balasubramanian et al., 2013). It is not the purpose of this opinion article to go into the details of the mechanisms at the basis of the switch, but rather to emphasize the importance of this duality in relation to iron uptake systems.

\section{THE TWO OXIDATION STATES OF IRON AND THEIR IMPORTANCE FOR BIOLOGICAL SYSTEMS}

Iron is the fourth most abundant element on earth and it is widely used by organisms because it can exist in two oxidation states, $\mathrm{Fe}^{2+}$ and $\mathrm{Fe}^{3+}$, which is why it is involved in numerous oxido-reduction reactions (Andrews et al., 2003). $\mathrm{Fe}^{3+}$ dominates in oxygenated environments, which presents a problem for microorganisms with an aerobic lifestyle because of the extremely low solubility of this form of the metal (Andrews et al., 2003). Conversely, the soluble $\mathrm{Fe}^{2+}$ is the most abundant form in anaerobic environments or in microaerobic conditions at low $\mathrm{pH}$ (Andrews et al., 2003).

\section{Pseudomonas aeruginosa USES MULTIPLE IRON UPTAKE SYSTEMS}

As already mentioned, bacterial pathogens are confronted with a problem of iron availability in the host since it is sequestered in the heme molecule or by circulating proteins such as transferrin or lactoferrin (Finkelstein et al., 1983; Cornelissen and Sparling, 1994). Although some pathogens, like Neisseria, are able 
to take-up iron directly from transferrin, this is not an option for

P. aeruginosa (Cornelissen, 2003; Noinaj et al., 2012).

$P$. aeruginosa can use different strategies to acquire iron:

- Via the production of extracellular $\mathrm{Fe}^{3+}$ chelating molecules termed siderophores (pyoverdine and pyochelin) and the uptake of ferrisiderophores via TonB-dependent receptors (TBDR).

- Via the uptake of xenosiderophores (not produced by the bacterium itself).

- Via the uptake of the heme molecule from the host hemoproteins.

- Via the extracellular reduction of $\mathrm{Fe}^{3+}$ to $\mathrm{Fe}^{2+}$ involving phenazine compounds and a $\mathrm{Fe}^{2+}$ dedicated iron uptake system, termed the Feo system.

Depending on the type of infection it causes (acute vs. chronic), $P$. aeruginosa can adapt its iron uptake strategy to best fulfill its needs for the metal without spending too much energy.

\section{THE $P$. aeruginosa PYOVERDINE AND PYOCHELIN-MEDIATED Fe ${ }^{3+}$ UPTAKE SYSTEMS}

Siderophores are low-molecular weight excreted molecules that specifically chelate $\mathrm{Fe}^{3+}$ with a high affinity and are taken up by specific receptors dependent on the energy provided by the TonB cytoplasmic membrane protein (Braun and Killmann, 1999; Boukhalfa and Crumbliss, 2002; Hider and Kong, 2011; Schalk et al., 2012; Schalk and Guillon, 2013). Siderophores are of different types, based on the way the iron is complexed: phenolate-, catecholate-, hydroxamate-, carboxylate-, or mixed type of siderophores have been described.

\section{PYOVERDINES: THE HIGH AFFINITY SIDEROPHORES ARE NEEDED TO CAUSE ACUTE INFECTIONS}

$P$. aeruginosa pyoverdine is a composite (mixed) siderophore comprising a peptide chain and a chromophore (Meyer, 2000; Ravel and Cornelis, 2003; Visca et al., 2007) and the structure of one $P$. aeruginosa pyoverdine (type I) is shown in Figure 1. Pyoverdines are the hallmark of fluorescent Pseudomonas species (P. fluorescens, P. putida, P. syringae, P. aeruginosa) and are produced when the bacteria are grown in low iron conditions (Meyer, 2000; Ravel and Cornelis, 2003; Visca et al., 2007). The conserved chromophore part of the molecule provides the catecholate function participating in the binding of $\mathrm{Fe}^{3+}$ while the peptide chain is highly variable among representatives of the different Pseudomonas species or even within a species (Meyer et al., 2008). Pyoverdines peptide chains contain between 6 and 12 amino-acids (Meyer, 2000; Ravel and Cornelis, 2003; Visca et al., 2007). Within the species $P$. aeruginosa, three different types of pyoverdines have been recognized, which differ by the composition of their respective peptide chain (Cornelis et al., 1989; Meyer et al., 1997). Pyoverdines bind iron with a very high affinity, are able to displace iron from transferrin and pyoverdine production is absolutely needed to cause infection in a burned mouse model or in case of mouse pulmonary infections (Albrecht-Gary et al., 1994; Meyer et al., 1996; Meyer, 2000; Takase et al., 2000a,b; Imperi et al., 2013). Likewise, a mutant in the TonB protein is

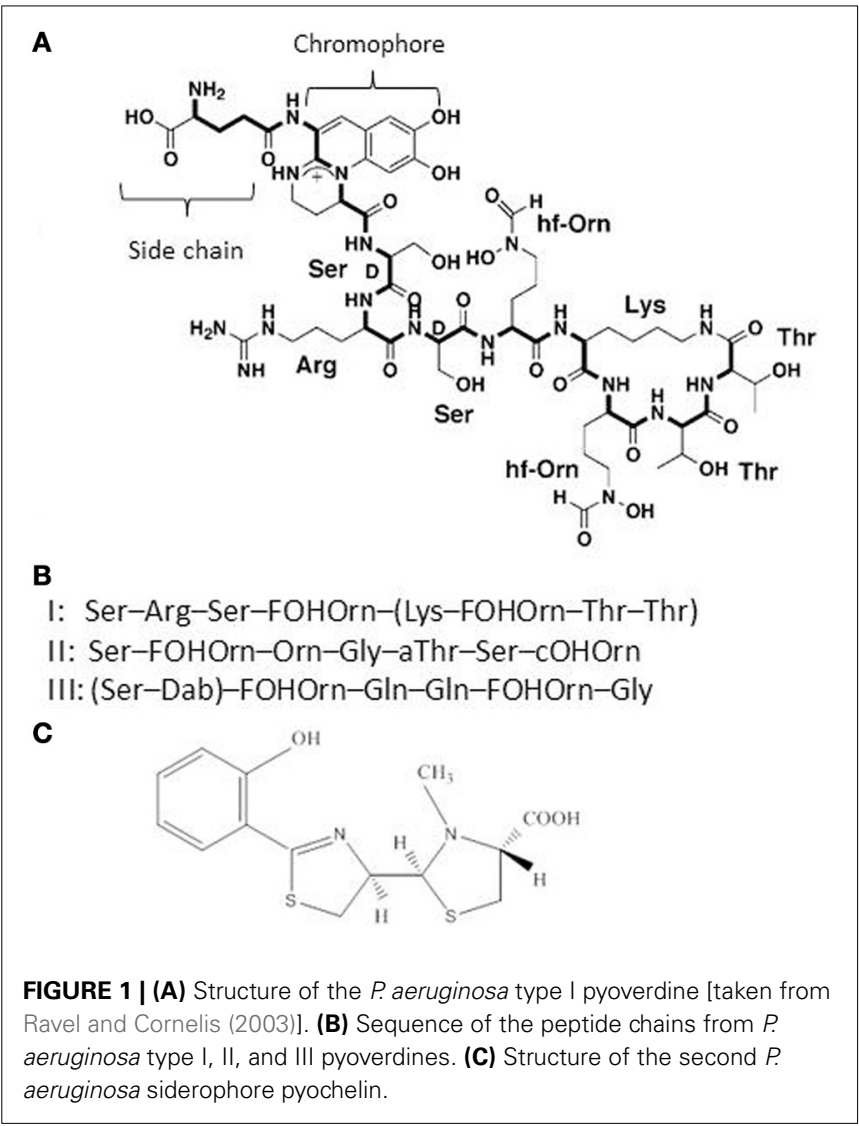

avirulent in a mouse model (Takase et al., 2000b). In their recent study, Imperi et al. screened different FDA-approved compounds for their inhibitory activity toward pyoverdine production by $P$. aeruginosa. One such compound, the antimycotic drug flucytosine, caused a strong decrease in pyoverdine production in several strains of $P$. aeruginosa producing the different pyoverdine types and the inhibitory activity was found to target the extracytoplasmic sigma factor (ECF $\sigma$ ) PvdS, which is needed for the transcription of pyoverdine biosynthesis genes (Imperi et al., 2013). Pyoverdine is not only a siderophore, but also a signal molecule since it triggers the production of two extracellular virulence factors, the protease PrpL and the potent toxin exotoxin A (Figure 2) (Lamont et al., 2002; Redly and Poole, 2003, 2005; Visca et al., 2007; Cornelis, 2010). Although pyoverdine seems to be essential to $P$. aeruginosa to cause acute infections, it has also been shown to be involved in the establishment of thick mature biofilms (Banin et al., 2005; Patriquin et al., 2008; Glick et al., 2010).

\section{PYOCHELIN: THE LOW-AFFINITY SIDEROPHORE}

Pyochelin (Figure 1), the second siderophore of $P$. aeruginosa, is produced by all $P$. aeruginosa isolates, but its affinity for iron is much lower compared to pyoverdine (Cox et al., 1981; Ankenbauer et al., 1988; Brandel et al., 2012). Pyochelin biosynthesis involves a lower number of genes compared to pyoverdine (Serino et al., 1997) and it has been recently demonstrated that $P$. aeruginosa first produces pyochelin and switches to pyoverdine 
production only when the concentration of iron becomes really low (Dumas et al., 2013). Pyochelin-iron can redox-cycle and has been shown to cause oxidative damage and inflammation, especially in the presence of another $P$. aeruginosa extracellular compound, pyocyanin (Coffman et al., 1990; Britigan et al., 1992, 1997). In chronic infections, such as in CF lungs, the production of pyochelin could play a role in the sustained inflammatory response which is known to occur and cause damage to tissues (Lyczak et al., 2002). It has been shown that pyochelin production is increased in a synthetic CF sputum medium (Hare et al., 2012).

\section{HEME UPTAKE SYSTEMS}

$P$. aeruginosa has the capacity to take up heme from hemoproteins via the two systems Has and Phu (Ochsner et al., 2000). Heme is not found in its free form because it is highly hydrophobic causing it to associate with membranes where it promotes non-enzymatic redox reactions (Wyckoff et al., 2005). Heme must therefore be extracted from hemoproteins such as hemoglobin or hemopexin. In the $P$. aeruginosa Phu system heme is directly extracted by an outer membrane TBDR while in the Has system, heme is first extracted by a secreted protein, the hemophore. The hemophoreheme complex is recognized by another TBDR, HasR (Letoffe et al., 1998; Wandersman and Delepelaire, 2004, 2012). Once in the periplasm, heme is bound by a periplasmic binding protein and transported to the cytoplasm by an $\mathrm{ABC}$ transporter where

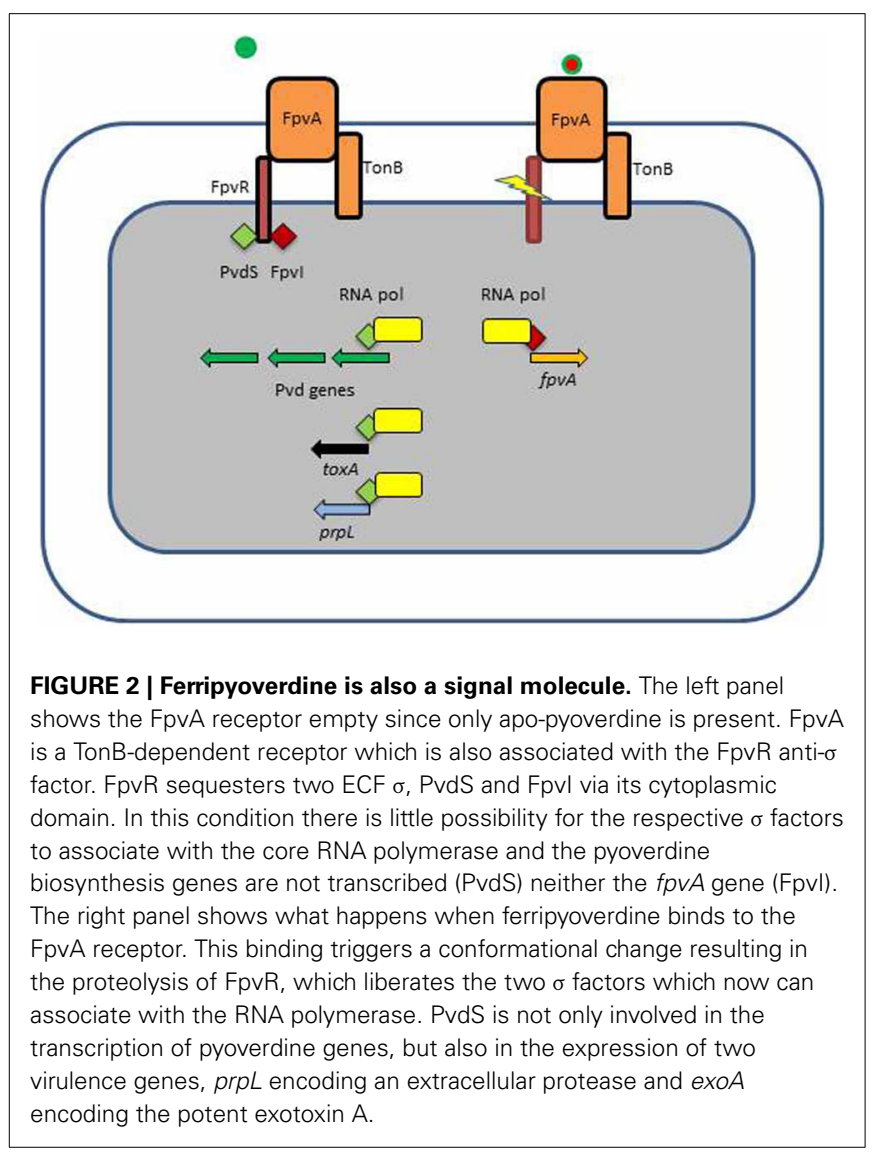

it is first bound to a heme chaperone, PhuS, before being delivered to the heme oxygenase $\mathrm{HemO}$ where the heme molecule will be degraded to form biliverdin, $\mathrm{CO}$, and $\mathrm{Fe}^{2+}$ (Bhakta and Wilks, 2006; Lansky et al., 2006; Barker et al., 2012; O’Neill et al., 2012). A single mutant in the phu system or in the has system is still able to take up heme while a double phu has mutant is virtually unable to use heme as a source of iron (Ochsner et al., 2000). The Phu and Has systems are schematically presented in Figure 3.

\section{UPTAKE OF XENOSIDEROPHORES}

$P$. aeruginosa strains have generally more than 30 genes encoding TBDRs, the majority of them involved in the uptake of ferrisiderophores (Bodilis et al., 2009; Cornelis and Bodilis, 2009; Cornelis et al., 2009). The different TBDRs can be classified into two categories, the simple TBDR and the TonB-dependent transducers (TBDT) (Hartney et al., 2011). The TBDT, of which the ferripyoverdine receptor FpvA is an example, can sense the presence of the cognate ferrisiderophore by interacting with a membrane protein which acts as an anti-sigma factor (Hartney et al., 2011). Upon recognition of the ferrisiderophore by the cognate receptor, the anti-sigma factor undergoes a proteolytic degradation liberating the extracytoplasmic sigma factor (ECF $\sigma$ ), which associates with the RNA polymerase to transcribe the receptor gene, causing an auto-induction reaction (Cornelis et al., 2009; Mettrick and Lamont, 2009; Cornelis, 2010; Hartney et al., 2011). The majority of $P$. aeruginosa strains (98\%) have a second receptor for type I ferripyoverdine, FpvB, which means that almost all strains have the capacity to use this pyoverdine as source of iron (Ghysels et al., 2004; Bodilis et al., 2009). P. aeruginosa is also able to utilize the $E$. coli siderophore enterobactin via two

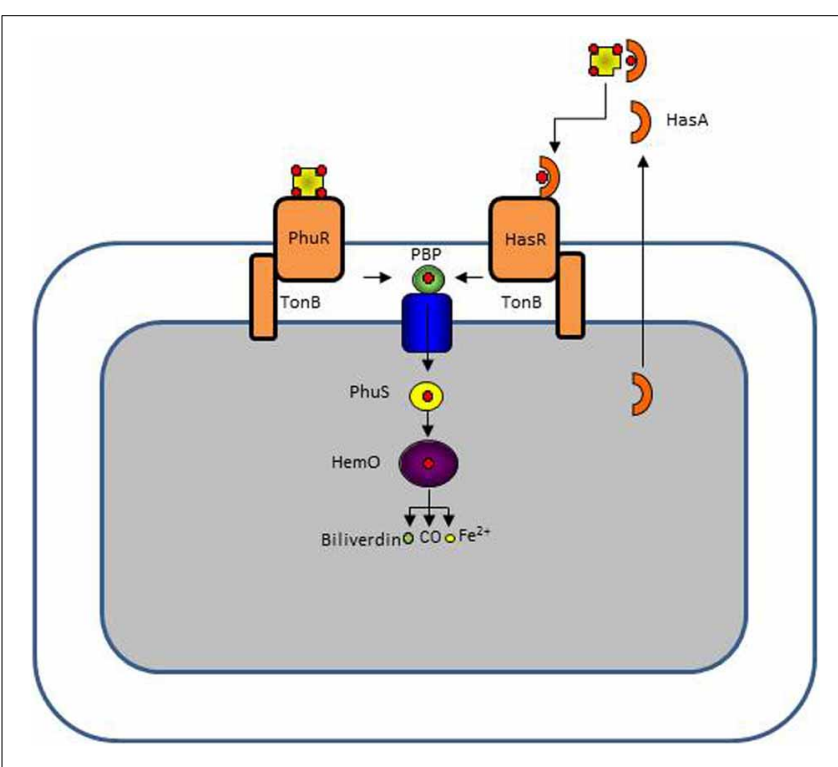

FIGURE 3 | P aeruginosa has two heme uptake systems, Phu, and Has. The PhuR TonB-dependent receptor binds directly hemoproteins extracting heme while the HasR receptor binds heme complexed to a secreted hemophore protein HasA. In the periplasm heme is bound to a periplasmic protein which delivers it to an $A B C$ transporter. In the cytoplasm heme is directed to the heme oxygenase $\mathrm{HemO}$ by the PhuS chaperone. HemO cleaves the tetrapyrrole ring, leaving biliverdin, $\mathrm{CO}$, and $\mathrm{Fe}^{2+}$. 
different receptors, PfeA and PirA since only a double $p f e A$ pirA mutant is unable to take up ferrienterobactin (Dean and Poole, 1993; Ghysels et al., 2005; Cornelis and Bodilis, 2009). Other characterized receptors are FoxB and FiuA for the uptake of ferrioxamine and ferrichrome (Llamas et al., 2006; Cuiv et al., 2007; Banin et al., 2008; Hannauer et al., 2010), FemA for the utilization of mycobactin and carboxymycobactin (Llamas et al., 2008), FecA for Fe-citrate uptake (Marshall et al., 2009), ChtA for rhizobactin, aerobactin, and schizokinen (Cuiv et al., 2006), and FvbA for the uptake of vibriobactin (Elias et al., 2011). However, the importance of these xenosiderophore uptake systems in infections has not, to the best of our knowledge, been established. They could however be of importance in case of polymicrobial infections where $P$. aeruginosa could be at advantage because of its capacity to steal siderophores produced by other microorganisms (siderophore piracy) (Traxler et al., 2012) while depriving the competitors from iron because they would be unable to recognize the complex pyoverdine siderophore.

\section{UPTAKE OF Fe ${ }^{2+}$ VIA THE Feo SYSTEM: INVOLVEMENT OF PHENAZINES}

Unlike $\mathrm{Fe}^{3+}, \mathrm{Fe}^{2+}$ is soluble and is present in anaerobic conditions or in microaerobic environments at lower $\mathrm{pH}$ (Andrews et al., 2003). $\mathrm{Fe}^{2+}$ probably diffuses through the outer membrane and is further transported inside the cytoplasm by the FeOABC system, which is present in many Gram-negative bacteria (Cartron et al., 2006). The soluble $\mathrm{Fe}^{2+}$ is transported inside the cells via a transport system composed of the permease FeoB, and the proteins FeoA and FeoC (Cartron et al., 2006). The uptake of $\mathrm{Fe}^{2+}$ by $P$. aeruginosa is probably relevant when the bacterium finds itself in a microaerobic or anaerobic environment, a situation known to exist in the CF lung mucus where $P$. aeruginosa forms biofilms (Worlitzsch et al., 2002; Yoon et al., 2002). Phenazines are secondary metabolites produced by $P$. aeruginosa (Figure 4). Phenazine-1-carboxylic acid (PCA) is the precursor of pyocyanin, a blue-green compound typical of $P$. aeruginosa, and both phenazine compounds can redoxcycle (Wang and Newman, 2008). PCA, and to a lesser extent pyocyanin, is able to reduce $\mathrm{Fe}^{3+}$ bound to host proteins to $\mathrm{Fe}^{2+}$, allowing the uptake of iron in biofilms via the Feo system (Figure 4) (Wang et al., 2011). Recently, it was demonstrated that both phenazines and $\mathrm{Fe}^{2+}$ accumulate in the lungs of CF patients when their condition deteriorates (Hunter et al., 2012, 2013). In their last article, Hunter et al. (2013) also show that maximal $P$. aeruginosa biofilm disruption is achieved using a combination of both $\mathrm{Fe}^{3+}$ and $\mathrm{Fe}^{2+}$ chelators.

\section{ADAPTATION OF P. aeruginosa IRON UPTAKE STRATEGIES: THE EXAMPLE OF CF LUNG INFECTIONS}

As already mentioned, $P$. aeruginosa can switch from the production of pyochelin, the low affinity siderophore, to the more energy demanding high affinity pyoverdine in function of the availability of $\mathrm{Fe}^{3+}$ (Dumas et al., 2013). One typical example is the adaptation of $P$. aeruginosa to the CF lung environment (Lyczak et al., 2002). When $P$. aeruginosa invades the lungs, it is probably able to produce pyoverdine, but with longer colonization times the bacterium induces a strong inflammatory response, due to the production of pyochelin among other causes, resulting in tissue damage and release of cellular contents, including hemoproteins and other iron-containing proteins (Britigan et al., 1997). Although siderophores, including pyoverdine, have been detected in the sputum samples of CF patients (Martin et al., 2011), pyoverdine-negative mutants accumulate with longer times of colonization (De Vos et al., 2001; Lamont et al., 2009), suggesting

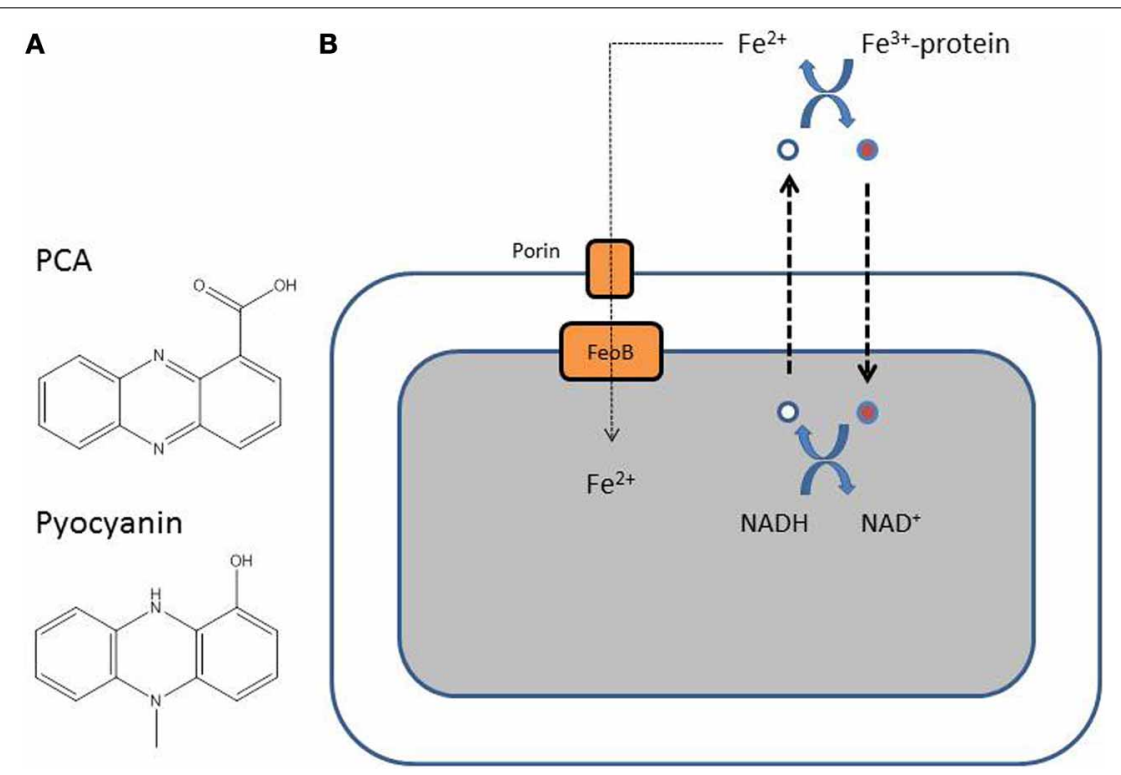

FIGURE 4 | (A) Structure of the two major $P$. aeruginosa phenazines, phenazine-1-carboxylic acid (PCA), and pyocyanin. (B) Reduced PCA (white-filled circle) is excreted out of the cell and is oxidized (red-filled circle) resulting in the reduction of $\mathrm{Fe}^{3+}$ to $\mathrm{Fe}^{2+}$. The oxidized phenazine is recycled inside the cell where it is reduced again with simultaneous oxidation of NADH to NAD (Wang et al., 2011). 
that alternative systems are used by $P$. aeruginosa to fulfill its needs for iron. This is the case since $P$. aeruginosa can take up heme from hemoproteins released by the inflammatory process and $\mathrm{Fe}^{2+}$ generated by the redox activity of phenazines, in particular PCA (Lamont et al., 2009; Wang et al., 2011; Hunter et al., 2013; Konings et al., 2013).

\section{CONCLUSIONS}

From the analysis of the abundant literature on $P$. aeruginosa iron uptake systems, it is clear that this bacterium can exquisitely adapt its iron capture strategy in function of the type of infection it causes. When causing acute infections, it uses its high-affinity pyoverdine siderophore, which at the same time acts as a signal molecule for the production of acute virulence factors. On the other hand, when establishing itself in a niche where it can persist and cause inflammation, it tends to lose its capacity to produce pyoverdine and to rely on alternative iron uptake strategies, including the uptake of heme from hemoproteins and the uptake of $\mathrm{Fe}^{2+}$ generated via the redox activity of phenazines. This has certainly implications in terms of finding treatments based on iron chelation since not only $\mathrm{Fe}^{3+}$ scavenging should be considered (Ballouche et al., 2009; Hunter et al., 2013).

\section{REFERENCES}

Albrecht-Gary, A. M., Blanc, S., Rochel N., Ocacktan, A. Z., and Abdallah, M. A. (1994). Bacterial iron transport: coordination properties of pyoverdin $\mathrm{PaA}$, a peptidic siderophore of Pseudomonas aeruginosa. Inorg. Chem. 33, 6391-6402. doi: 10.1021/ic00104a059

Andrews, S. C., Robinson, A. K., and Rodriguez-Quinones, F. (2003). Bacterial iron homeostasis. FEMS Microbiol. Rev. 27, 215-237. doi: 10.1016/S01686445(03)00055-X

Ankenbauer, R. G., Toyokuni, T., Staley, A., Rinehart, K. L. Jr., and Cox, C. D. (1988). Synthesis and biological activity of pyochelin, a siderophore of Pseudomonas aeruginosa. J. Bacteriol. 170, 5344-5351.

Balasubramanian, D., Schneper, L., Kumari, H., and Mathee, K. (2013). A dynamic and intricate regulatory network determines Pseudomonas aeruginosa virulence. Nucl. Acids Res. 41, 1-20. doi: 10.1093/nar/gks1039

Ballouche, M., Cornelis, P., and Baysse, C. (2009). Iron metabolism: a promising target for antibacterial strategies. Recent Pat. Antiinfect. Drug Discov. 4, 190-205. doi: 10.2174/157489109789318514

Banin, E., Lozinski, A., Brady, K. M., Berenshtein, E., Butterfield, P. W., Moshe, M., et al. (2008). The potential of desferrioxamine-gallium as an antiPseudomonas therapeutic agent. Proc. Natl. Acad. Sci. U.S.A. 105, 16761-16766. doi: 10.1073/pnas.0808608105

Banin, E., Vasil, M. L., and Greenberg, E. P. (2005). Iron and Pseudomonas aeruginosa biofilm formation. Proc. Natl. Acad. Sci. U.S.A. 102, 11076-11081. doi: 10.1073/pnas.0504266102

Barker, K. D., Barkovits, K., and Wilks, A. (2012). Metabolic flux of extracellular heme uptake in Pseudomonas aeruginosa is driven by the ironregulated heme oxygenase (HemO). J. Biol. Chem. 287, 18342-18350. doi: 10.1074/jbc.M112.359265

Bhakta, M. N., and Wilks, A. (2006). The mechanism of heme transfer from the cytoplasmic heme binding protein PhuS to the delta-regioselective heme oxygenase of Pseudomonas aeruginosa. Biochemistry 45, 11642-11649. doi: 10.1021/bi060980l

Bodilis, J., Ghysels, B., Osayande, J., Matthijs, S., Pirnay, J. P., Denayer, S., et al. (2009). Distribution and evolution of ferripyoverdine receptors in Pseudomonas aeruginosa. Environ. Microbiol. 11, 2123-2135. doi: 10.1111/j.1462-2920.2009.01932.x

Boukhalfa, H., and Crumbliss, A. L. (2002). Chemical aspects od siderophore mediated iron transport. Biometals 15, 325-339. doi: 10.1023/A:1020218608266

Brandel, J., Humbert, N., Elhabiri, M., Schalk, I. J., Mislin, G. L., and Albrecht-Gary, A. M. (2012). Pyochelin, a siderophore of Pseudomonas aeruginosa: physicochemical characterization of the iron(III), copper(II) and zinc(II) complexes. Dalton Trans. 41, 2820-2834. doi: 10.1039/cldt $11804 \mathrm{~h}$

Braun, V., and Killmann, H. (1999). Bacterial solutions to the iron-supply problem. Trends Biochem. Sci. 24, 104-109. doi: 10.1016/S0968-0004(99) 01359-6

Britigan, B. E., Rasmussen, G. T., and Cox, C. D. (1997). Augmentation of oxidant injury to human pulmonary epithelial cells by the Pseudomonas aeruginosa siderophore pyochelin. Infect. Immun. 65, 1071-1076.

Britigan, B. E., Roeder, T. L., Rasmussen, G. T., Shasby, D. M., McCormick, M. L., and Cox, C. D. (1992). Interaction of the Pseudomonas aeruginosa secretory products pyocyanin and pyochelin generates hydroxyl radical and causes synergistic damage to endothelial cells. Implications for Pseudomonasassociated tissue injury. J. Clin. Invest. 90, 2187-2196. doi: 10.1172/ JCI1 16104

Cartron, M. L., Maddocks, S., Gillingham, P., Craven, C. J., and Andrews, S. C. (2006). Feo-transport of ferrous iron into bacteria. Biometals 19, 143-157. doi: 10.1007/s10534-006-0003-2

Coffman, T. J., Cox, C. D., Edeker, B. L., and Britigan, B. E. (1990). Possible role of bacterial siderophores in inflammation. Iron bound to the Pseudomonas siderophore pyochelin can function as a hydroxyl radical catalyst. J. Clin. Invest. 86, 1030-1037. doi: 10.1172/JCI114805

Coggan, K. A., and Wolfgang, M. C. (2012). Global regulatory pathways and crosstalk control Pseudomonas aeruginosa environmental lifestyle and virulence phenotype. Curr. Issues Mol. Biol. 14, 47-70.

Cornelis, P. (2010). Iron uptake and metabolism in pseudomonads. Appl. Microbiol. Biotechnol. 86, 1637-1645. doi: 10.1007/s00253-010-2550-2

Cornelis, P., and Bodilis, J. (2009). A survey of TonB-dependent receptors in fluorescent pseudomonads. Environ. Microbiol. Reports 1, 256-262. doi: 10.1111/j.1758-2229.2009.00041.x

Cornelis, P., Hohnadel, D., and Meyer, J. M. (1989). Evidence for different pyoverdine-mediated iron uptake systems among Pseudomonas aeruginosa strains. Infect. Immun. 57, 3491-3497.

Cornelis, P., Matthijs, S., and Van Oeffelen, L. (2009). Iron uptake regulation in Pseudomonas aeruginosa. Biometals 22, 15-22. doi: 10.1007/s10534-008-9193-0

Cornelissen, C. N. (2003). Transferrin-iron uptake by Gram-negative bacteria. Front. Biosci. 8, d836-d847. doi: 10.2741/1076

Cornelissen, C. N., and Sparling, P. F. (1994). Iron piracy: acquisition of transferrin-bound iron by bacterial pathogens. Mol. Microbiol. 14, 843-850. doi: 10.1111/j.1365-2958.1994.tb01320.x

Cox, C. D., Rinehart, K. L. Jr., Moore, M. L., and Cook, J. C. Jr. (1981). Pyochelin: novel structure of an iron-chelating growth promoter for Pseudomonas aeruginosa. Proc. Natl. Acad. Sci. U.S.A. 78, 4256-4260. doi: 10.1073/pnas.78.7.4256

Cuiv, P. O., Clarke, P., and O'Connell, M. (2006). Identification and characterization of an iron-regulated gene, chtA, required for the utilization of the xenosiderophores aerobactin, rhizobactin 1021 and schizokinen by Pseudomonas aeruginosa. Microbiology 152, 945-954. doi: 10.1099/mic.0.28552-0

Cuiv, P. O., Keogh, D., Clarke, P., and O'Connell, M. (2007). FoxB of Pseudomonas aeruginosa functions in the utilization of the xenosiderophores ferrichrome, ferrioxamine $B$, and schizokinen: evidence for transport redundancy at the inner membrane. J. Bacteriol. 189, 284-287. doi: 10.1128/JB. 01142-06

Dean, C. R., and Poole, K. (1993). Cloning and characterization of the ferric enterobactin receptor gene (pfeA) of Pseudomonas aeruginosa. J. Bacteriol. 175, 317-324.

De Vos, D., De Chial, M., Cochez, C., Jansen, S., Tummler, B., Meyer, J. M., et al. (2001). Study of pyoverdine type and production by Pseudomonas aeruginosa isolated from cystic fibrosis patients: prevalence of type II pyoverdine isolates and accumulation of pyoverdine-negative mutations. Arch. Microbiol. 175, 384-388. doi:10.1007/s002030100278

Dumas, Z., Ross-Gillespie, A., and Kümmerli, R. (2013). Switching between apparently redundant iron-uptake mechanisms benefits bacteria in changeable environments. Proc. R. Soc. B 280, 20131055. doi: 10.1098/rspb.2013.1055

Elias, S., Degtyar, E., and Banin, E. (2011). FvbA is required for vibriobactin utilization in Pseudomonas aeruginosa. Microbiology 157, 2172-2180. doi: 10.1099/mic.0.044768-0

Finkelstein, R. A., Sciortino, C. V., and McIntosh, M. A. (1983). Role of iron in microbe-host interactions. Rev. Infect. Dis. 5(Suppl. 4), S759-S777. doi: 10.1093/clinids/5.Supplement_4.S759 
Ghysels, B., Dieu, B. T., Beatson, S. A., Pirnay, J. P., Ochsner, U. A., Vasil, M. L., et al. (2004). FpvB, an alternative type I ferripyoverdine receptor of Pseudomonas aeruginosa. Microbiology 150, 1671-1680. doi: 10.1099/mic.0.27035-0

Ghysels, B., Ochsner, U., Mollman, U., Heinisch, L., Vasil, M., Cornelis, P., et al. (2005). The Pseudomonas aeruginosa pirA gene encodes a second receptor for ferrienterobactin and synthetic catecholate analogues. FEMS Microbiol. Lett. 246, 167-174. doi: 10.1016/j.femsle.2005.04.010

Girard, G., and Bloemberg, G. V. (2008). Central role of quorum sensing in regulating the production of pathogenicity factors in Pseudomonas aeruginosa. Future Microbiol. 3, 97-106. doi: 10.2217/17460913.3.1.97

Glick, R., Gilmour, C., Tremblay, J., Satanower, S., Avidan, O., Deziel, E., et al. (2010). Increase in rhamnolipid synthesis under iron-limiting conditions influences surface motility and biofilm formation in Pseudomonas aeruginosa. J. Bacteriol. 192, 2973-2980. doi: 10.1128/JB.01601-09

Goldberg, J. B. (2000). Pseudomonas: global bacteria. Trends Microbiol. 8, 55-57. doi: 10.1016/S0966-842X(99)01671-6

Goodman, A. L., Kulasekara, B., Rietsch, A., Boyd, D., Smith, R. S., and Lory, S. (2004). A signaling network reciprocally regulates genes associated with acute infection and chronic persistence in Pseudomonas aeruginosa. Dev. Cell 7, 745-754. doi: 10.1016/j.devcel.2004.08.020

Hannauer, M., Barda, Y., Mislin, G. L., Shanzer, A., and Schalk, I. J. (2010). The ferrichrome uptake pathway in Pseudomonas aeruginosa involves an iron release mechanism with acylation of the siderophore and recycling of the modified desferrichrome. J. Bacteriol. 192, 1212-1220. doi: 10.1128/JB.01539-09

Hare, N. J., Soe, C. Z., Rose, B., Harbour, C., Codd, R., Manos, J., et al. (2012). Proteomics of Pseudomonas aeruginosa Australian epidemic strain 1 (AES-1) cultured under conditions mimicking the cystic fibrosis lung reveals increased iron acquisition via the siderophore pyochelin. J. Proteome Res. 11, 776-795. doi: $10.1021 /$ pr200659h

Hartney, S. L., Mazurier, S., Kidarsa, T. A., Quecine, M. C., Lemanceau, P., and Loper, J. E. (2011). TonB-dependent outer-membrane proteins and siderophore utilization in Pseudomonas fluorescens Pf-5. Biometals 24, 193-213. doi: 10.1007/s10534-010-9385-2

Hider, R. C. and Kong, X. (2011). Chemistry and biology of siderophores. Nat. Prod. Rep. 27, 637-657. doi: 10.1039/b906679a

Hunter, R. C., Asfour, F., Dingemans, J., Osuna, B. L., Samad, T., Malfroot, A., et al. (2013). Ferrous iron is a significant component of bioavailable iron in cystic fibrosis airways. MBio 4:e0557-13. doi: 10.1128/mBio.00557-13

Hunter, R. C., Klepac-Ceraj, V., Lorenzi, M. M., Grotzinger, H., Martin, T. R., and Newman, D. K. (2012). Phenazine content in the cystic fibrosis respiratory tract negatively correlates with lung function and microbial complexity. Am. J. Respir. Cell Mol. Biol. 47, 738-745. doi: 10.1165/rcmb.2012-0088OC

Imperi, F., Massai, F., Facchini, M., Frangipani, E., Visaggio, D., Leoni, L., et al. (2013). Repurposing the antimycotic drug flucytosine for suppression of Pseudomonas aeruginosa pathogenicity. Proc. Natl. Acad. Sci. U.S.A. 110, 7458-7463. doi: 10.1073/pnas.1222706110

Jimenez, P. N., Koch, G., Thompson, J. A., Xavier, K. B., Cool, R. H., and Quax, W. J. (2012). The multiple signaling systems regulating virulence in Pseudomonas aeruginosa. Microbiol. Mol. Biol. Rev. 76, 46-65. doi: 10.1128/MMBR.05007-11

Juhas, M., Eberl, L., and Tummler, B. (2005). Quorum sensing: the power of cooperation in the world of Pseudomonas. Environ. Microbiol. 7, 459-471. doi: 10.1111/j.1462-2920.2005.00769.x

Konings, A. F., Martin, L. W., Sharples, K. J., Roddam, L. F., Latham, R., Reid, D. W., et al. (2013). Pseudomonas aeruginosa uses multiple pathways to acquire iron during chronic infection in cystic fibrosis lungs. Infect. Immun. 81, 2697-2704. doi: 10.1128/IAI.00418-13

Lamont, I. L., Beare, P. A., Ochsner, U., Vasil, A. I., and Vasil, M. L. (2002). Siderophore-mediated signaling regulates virulence factor production in Pseudomonas aeruginosa. Proc. Natl. Acad. Sci. U.S.A. 99, 7072-7077. doi: 10.1073/pnas.092016999

Lamont, I. L., Konings, A. F., and Reid, D. W. (2009). Iron acquisition by Pseudomonas aeruginosa in the lungs of patients with cystic fibrosis. Biometals 22, 53-60. doi: 10.1007/s10534-008-9197-9

Lansky, I. B., Lukat-Rodgers, G. S., Block, D., Rodgers, K. R., Ratliff, M., and Wilks, A. (2006). The cytoplasmic heme-binding protein (PhuS) from the heme uptake system of Pseudomonas aeruginosa is an intracellular heme-trafficking protein to the delta-regioselective heme oxygenase. J. Biol. Chem. 281, 13652-13662. doi: 10.1074/jbc.M600824200
Letoffe, S., Redeker, V., and Wandersman, C. (1998). Isolation and characterization of an extracellular haem-binding protein from Pseudomonas aeruginosa that shares function and sequence similarities with the Serratia marcescens HasA haemophore. Mol. Microbiol. 28, 1223-1234. doi: 10.1046/j.13652958.1998.00885.x

Llamas, M. A., Mooij, M. J., Sparrius, M., Vandenbroucke-Grauls, C. M., Ratledge, C., and Bitter, W. (2008). Characterization of five novel Pseudomonas aeruginosa cell-surface signalling systems. Mol. Microbiol. 67, 458-472. doi: 10.1111/j.13652958.2007.06061.x

Llamas, M. A., Sparrius, M., Kloet, R., Jimenez, C. R., Vandenbroucke-Grauls, C., and Bitter, W. (2006). The heterologous siderophores ferrioxamine B and ferrichrome activate signaling pathways in Pseudomonas aeruginosa. J. Bacteriol. 188, 1882-1891. doi: 10.1128/JB.188.5.1882-1891.2006

Lyczak, J. B., Cannon, C. L., and Pier, G. B. (2000). Establishment of Pseudomonas aeruginosa infection: lessons from a versatile opportunist. Microbes and infection/Institut Pasteur 2, 1051-1060. doi: 10.1016/S1286-4579(00)01259-4

Lyczak, J. B., Cannon, C. L., and Pier, G. B. (2002). Lung infections associated with cystic fibrosis. Clin. Microbiol. Rev. 15, 194-222. doi: 10.1128/CMR.15.2.194222.2002

Mahajan-Miklos, S., Tan, M. W., Rahme, L. G., and Ausubel, F. M. (1999). Molecular mechanisms of bacterial virulence elucidated using a Pseudomonas aeruginosa-Caenorhabditis elegans pathogenesis model. Cell 96, 47-56. doi: 10.1016/S0092-8674(00)80958-7

Marshall, B., Stintzi, A., Gilmour, C., Meyer, J. M., and Poole, K. (2009). Citratemediated iron uptake in Pseudomonas aeruginosa: involvement of the citrateinducible FecA receptor and the FeoB ferrous iron transporter. Microbiology 155, 305-315. doi: 10.1099/mic.0.023531-0

Martin, L. W., Reid, D. W., Sharples, K. J., and Lamont, I. L. (2011). Pseudomonas siderophores in the sputum of patients with cystic fibrosis. Biometals 24, 1059-1067. doi: 10.1007/s10534-011-9464-z

Mettrick, K. A., and Lamont, I. L. (2009). Different roles for anti-sigma factors in siderophore signalling pathways of Pseudomonas aeruginosa. Mol. Microbiol. 74, 1257-1271. doi: 10.1111/j.1365-2958.2009.06932.x

Meyer, J. M. (2000). Pyoverdines: pigments, siderophores and potential taxonomic markers of fluorescent Pseudomonas species. Arch. Microbiol. 174, 135-142. doi: $10.1007 / \mathrm{s} 0020300001$

Meyer, J. M., Gruffaz, C., Raharinosy, V., Bezverbnaya, I., Schafer, M., and Budzikiewicz, H. (2008). Siderotyping of fluorescent Pseudomonas: molecular mass determination by mass spectrometry as a powerful pyoverdine siderotyping method. Biometals 21, 259-271. doi: 10.1007/s10534-0079115-6

Meyer, J. M., Neely, A., Stintzi, A., Georges, C., and Holder, I. A. (1996). Pyoverdin is essential for virulence of Pseudomonas aeruginosa. Infect Immun 64, 518-523.

Meyer, J. M., Stintzi, A., De Vos, D., Cornelis, P., Tappe, R., Taraz, K., et al. (1997). Use of siderophores to type pseudomonads: the three Pseudomonas aeruginosa pyoverdine systems. Microbiology 143, 35-43. doi: 10.1099/00221287143-1-35

Mikkelsen, H., McMullan, R., and Filloux, A. (2011). The Pseudomonas aeruginosa reference strain PA14 displays increased virulence due to a mutation in ladS. PLoS ONE 6:e29113. doi: 10.1371/journal.pone.0029113

Noinaj, N., Buchanan, S. K., and Cornelissen, C. N. (2012). The transferrin-iron import system from pathogenic Neisseria species. Mol. Microbiol. 86, 246-257. doi: $10.1111 / \mathrm{mmi} .12002$

Ochsner, U. A., Johnson, Z., and Vasil, M. L. (2000). Genetics and regulation of two distinct haem-uptake systems, phu and has, in Pseudomonas aeruginosa. Microbiology 146, 185-198.

O’Neill, M. J., Bhakta, M. N., Fleming, K. G., and Wilks, A. (2012). Induced fit on heme binding to the Pseudomonas aeruginosa cytoplasmic protein (PhuS) drives interaction with heme oxygenase (HemO). Proc. Natl. Acad. Sci. U.S.A. 109, 5639-5644. doi: 10.1073/pnas.1121549109

Patriquin, G. M., Banin, E., Gilmour, C., Tuchman, R., Greenberg, E. P., and Poole, K. (2008). Influence of quorum sensing and iron on twitching motility and biofilm formation in Pseudomonas aeruginosa. J. Bacteriol. 190, 662-671. doi: 10.1128/JB.01473-07

Pukatzki, S., Kessin, R. H., and Mekalanos, J. J. (2002). The human pathogen Pseudomonas aeruginosa utilizes conserved virulence pathways to infect the social amoeba Dictyostelium discoideum. Proc. Natl. Acad. Sci. U.S.A. 99, 3159-3164. doi: 10.1073/pnas.052704399 
Rahme, L. G., Tan, M. W., Le, L., Wong, S. M., Tompkins, R. G., Calderwood, S. B., et al. (1997). Use of model plant hosts to identify Pseudomonas aeruginosa virulence factors. Proc. Natl. Acad. Sci. U.S.A. 94, 13245-13250. doi: 10.1073/pnas.94.24.13245

Ravel, J., and Cornelis, P. (2003). Genomics of pyoverdine-mediated iron uptake in pseudomonads. Trends Microbiol. 11, 195-200. doi: 10.1016/S0966842X(03)00076-3

Redly, G. A., and Poole, K. (2003). Pyoverdine-mediated regulation of FpvA synthesis in Pseudomonas aeruginosa: involvement of a probable extracytoplasmic-function sigma factor, FpvI. J. Bacteriol. 185, 1261-1265. doi: 10.1128/JB.185.4.1261-1265.2003

Redly, G. A., and Poole, K. (2005). FpvIR control of fpvA ferric pyoverdine receptor gene expression in Pseudomonas aeruginosa: demonstration of an interaction between FpvI and FpvR and identification of mutations in each compromising this interaction. J. Bacteriol. 187, 5648-5457. doi: 10.1128/JB.187.16.56485657.2005

Schalk, I. J. and Guillon, L. (2013). Fate of ferrisiderophores after import across bacterial outer membranes: different iron release strategies are observed in the cytoplasm or periplasm depending on the siderophore pathways. Amino Acids 44, 1267-1277. doi: 10.1007/s00726-0131468-2

Schalk, I. J., Mislin, G. L. and Brillet, K. (2012). Structure, function and binding selectivity and stereoselectivity of siderophore-iron outer membrane transporters. Curr. Top. Membr. 69, 37-66. doi: 10.1016/B978-0-12-394390-3. 00002-1

Schuster, M., and Greenberg, E. P. (2006). A network of networks: quorum-sensing gene regulation in Pseudomonas aeruginosa. Int. J. Med.Microbiol. 296, 73-81. doi: 10.1016/j.ijmm.2006.01.036

Serino, L., Reimmann, C., Visca, P., Beyeler, M., Chiesa, V. D., and Haas, D. (1997). Biosynthesis of pyochelin and dihydroaeruginoic acid requires the iron-regulated pchDCBA operon in Pseudomonas aeruginosa. J. Bacteriol. 179, 248-257.

Takase, H., Nitanai, H., Hoshino, K. and Otani, T. (2000a). Impact of siderophore production on Pseudomonas aeruginosa infections in immunosuppressed mice. Infect. Immun. 68, 1834-1839. doi: 10.1128/IAI.68.4.1834-1839.2000

Takase, H., Nitanai, H., Hoshino, K. and Otani, T. (2000b). Requirement of the Pseudomonas aeruginosa ton $\mathrm{B}$ gene for high-affinity iron acquisition and infection. Infect. Immun. 68, 4498-4504. doi: 10.1128/IAI.68.8.44984504.2000

Traxler, M. F., Seyedsayamdost, M. R., Clardy, J., and Kolter, R. (2012). Interspecies modulation of bacterial development through iron competition and siderophore piracy. Mol. Microbiol. 86, 628-644. doi: 10.1111/mmi.12008

Venturi, V. (2006). Regulation of quorum sensing in Pseudomonas. FEMS Microbiol. Rev. 30, 274-291. doi: 10.1111/j.1574-6976.2005.00012.x

Visca, P., Imperi, F., and Lamont, I. L. (2007). Pyoverdine siderophores: from biogenesis to biosignificance. Trends Microbiol. 15, 22-30. doi: 10.1016/j.tim.2006.11.004
Wandersman, C., and Delepelaire, P. (2004). Bacterial iron sources: from siderophores to hemophores. Annu. Rev. Microbiol. 58, 611-647. doi: 10.1146/annurev.micro.58.030603.123811

Wandersman, C., and Delepelaire, P. (2012). Haemophore functions revisited. Mol. Microbiol. 85, 618-631. doi: 10.1111/j.1365-2958.2012.08136.x

Wang, Y., and Newman, D. K. (2008). Redox reactions of phenazine antibiotics with ferric (hydr)oxides and molecular oxygen. Environ. Sci. Technol. 42, 2380-2386. doi: 10.1021/es702290a

Wang, Y., Wilks, J. C., Danhorn, T., Ramos, I., Croal, L., and Newman, D. K. (2011). Phenazine-1-carboxylic acid promotes bacterial biofilm development via ferrous iron acquisition. J. Bacteriol. 193, 3606-3617. doi: 10.1128/JB.00396-11

Williams, P., Winzer, K., Chan, W. C., and Camara, M. (2007). Look who's talking: communication and quorum sensing in the bacterial world. Philos. Trans. $R$. Soc. Series B Biol. Sci. 362, 1119-1134. doi: 10.1098/rstb.2007.2039

Winstanley, C., and Fothergill, J. L. (2009). The role of quorum sensing in chronic cystic fibrosis Pseudomonas aeruginosa infections. FEMS Microbiol. Lett. 290, 1-9. doi: 10.1111/j.1574-6968.2008.01394.x

Worlitzsch, D., Tarran, R., Ulrich, M., Schwab, U., Cekici, A., Meyer, K. C., et al. (2002). Effects of reduced mucus oxygen concentration in airway Pseudomonas infections of cystic fibrosis patients. J. Clin. Invest. 109, 317-325. doi: 10.1172/JCI13870

Wyckoff, E. E., Lopreato, G. F., Tipton, K. A., and Payne, S. M. (2005). Shigella dysenteriae ShuS promotes utilization of heme as an iron source and protects against heme toxicity. J. Bacteriol. 187, 5658-5664. doi: 10.1128/JB.187.16.56585664.2005

Yoon, S. S., Hennigan, R. F., Hilliard, G. M., Ochsner, U. A., Parvatiyar, K., Kamani, M. C., et al. (2002). Pseudomonas aeruginosa anaerobic respiration in biofilms: relationships to cystic fibrosis pathogenesis. Dev. Cell 3, 593-603. doi: 10.1016/S1534-5807(02)00295-2

Conflict of Interest Statement: The authors declare that the research was conducted in the absence of any commercial or financial relationships that could be construed as a potential conflict of interest.

Received: 02 October 2013; paper pending published: 11 October 2013; accepted: 22 October 2013; published online: 14 November 2013.

Citation: Cornelis P and Dingemans J (2013) Pseudomonas aeruginosa adapts its iron uptake strategies in function of the type of infections. Front. Cell. Infect. Microbiol. 3:75. doi: $10.3389 /$ fcimb.2013.00075

This article was submitted to the journal Frontiers in Cellular and Infection Microbiology.

Copyright (c) 2013 Cornelis and Dingemans. This is an open-access article distributed under the terms of the Creative Commons Attribution License (CC BY). The use, distribution or reproduction in other forums is permitted, provided the original author(s) or licensor are credited and that the original publication in this journal is cited, in accordance with accepted academic practice. No use, distribution or reproduction is permitted which does not comply with these terms. 